\title{
PERSISTING STRUCTURAL ALTERATIONS IN THE UTERUS AND OVARIES OF RATS INDUCED BY INTRAUTERINE DEVICES
}

\author{
A. POLLAK, M. GELLMAN* AND L. NEBEL \\ Department of Embryology and Teratology, Tel Aviv University Medical School, \\ Tel-Hashomer Hospital, Tel Aviv, Israel, and *Department of Obstetrics and Gynecology, \\ Bikur Holim Hospital, Jerusalem, Israel
}

(Received 14th September 1972)

Alterations induced in the endometrium by IUDs and their mechanism of action, impeding pregnancy, have been widely discussed (Willson, Ledger \& Andrios, 1965; Ledger, Virkar \& Irvin, 1966; Batta \& Chaudhury, 1968; Craig, 1969; DeBoer \& Anderson, 1971; Warren \& Hawk, 1971). Varying observations were reported on clinical material (Willson et al., 1965; Ober, Sobrero, Kurman \& Gold, 1968; Sagiroglu, 1971) and diverse endometrial injuries were induced in animals (Corfman \& Ritchart, 1967; Craig, 1967; Sudha, Chakravarti \& Chaudhury, 1967; Moore \& Bo, 1971). In the present study, the pathogenesis of lasting endometrial damage caused by long-term insertion of IUDs in experimental animals was investigated.

'Intramedic' polyethylene tubes No. 100 (Clay-Adams) were inserted at laparotomy into the length of the uterine horns of female albino rats (local breed, Charles River strain), weighing 150 to $200 \mathrm{~g}$ each. The proximal end of the exposed horn was incised, the tube was introduced and the incision was then sutured. A silk thread was tied supravaginally around the cervix or around the distal end of the horn. This prevented spontaneous expulsion of the tube but did not provoke circulatory disturbances.

The seventy-four animals were allocated to experimental and control groups. The IUD was inserted into both horns in twenty-two rats. In thirty-two rats, the IUD was inserted into the right horn only (treated horn, TH), the left horn serving for observation of modifications in the untreated contralateral horn (UCH) . About $40 \%$ of the experimental animals were killed with the tube in situ (TIS) between 7 and 30 days after its insertion. In the remaining experimental rats, the cervical ligature was released (PRS) at laparotomy on the same days, and the tube was rejected spontaneously during the following 2 to 3 days. These rats were allowed a 10- to 60-day recovery period following the second laparotomy and were repeatedly mated until autopsy.

The twenty control animals underwent laparotomy and a sham operation (the horns were proximally incised and sutured, and a pericervical ligature was tied but without insertion of an IUD) was performed on one horn (ten rats) or both horns (ten rats). In all the animals, the internal genital organs were examined at autopsy in situ and then removed, fixed in Bouin or formaldehyde 
solution, embedded in paraffin wax, sectioned at 6 to $8 \mu \mathrm{m}$ and stained with H. and E., periodic acid Schiff and Azan dyes.

Macroscopic examination of the TIS animals revealed that the treated horns were thickened and hyperaemic, with dilated lumina and eroded epithelia. Untreated concomitant horns were seen also to be thicker and slightly hyperaemic in many cases. Control animals were found to have normal genital organs 10 to 12 days after the sham operation.

The ovaries were enlarged and hyperaemic on both sides, even in those with unilateral IUDs. The ovarian changes were most prominent in animals bearing the tube for a longer period, where many enlarged and apparently cystic gonads were found.

Microscopically, the epithelium was extensively eroded, with severe polymorphonuclear and mononuclear infiltration in the stroma and intraluminally. Regenerating columnar epithelia with areas of hypertrophy and papillary formations were seen, containing many clear pale cells similar to 'Arias Stella cells'. The basal stroma was fibrotic with distinct eosinophilia, and the myometrium was hypertrophic and hyperaemic. The extent of the damage was related to the period during which the IUD was retained in the horn.

The epithelium in the treated horns of the rats in the PRS group began to regenerate as a hypertrophic layer which was later transformed into pseudostratified epithelium with many 'Arias Stella' cells. Later, epithelial hyperplasia appeared in several segments with metaplasia into stratified epithelium (Pl. 1, Fig. 1) in some sectors resembling the urinary tract epithelium. After a long period of recovery, many horns displayed squamous metaplasia with keratinization and a polypoid endometrium. Various transformations were present at the same time in different sectors of the same horn, from pseudostratified epithelium to squamous keratinizing metaplasia and polyposis (Table 1). Cystic endometrial glands with periglandular and intraluminal infiltration, and later, glandular cystic hyperplasia with metaplastic stratified epithelium and polyposis were observed. The stroma showed early polymorphonuclear and/or persisting mononuclear infiltration, oedema and hyperaemia; still later, very cellular stroma with diffuse eosinophilia and progressing fibrosis were observed in many horns (Pl. 1, Fig. 2), with a deep dense collagen layer (Table 2).

In the untreated horns of PRS rats, pseudostratified epithelium and hyperplasia to the stage of stratification resembling urinary tract epithelium were observed in some sectors. Glandular cystic hyperplasia was also seen. The stroma was hyperaemic with cellular infiltration and abundant eosinophilia, as well as some basal fibrosis. The stromal changes were less frequent and much less severe than in treated horns (Table 2).

Microscopic examination of the ovaries showed follicular cysts, atretic follicles and small lutein cysts, besides atypical early regressive corpora lutea of various ages. Later, enlarged cystic ovaries were seen, some showing multilocular large cysts. The ovaries of the contralateral side had a similar appearance, although these were less affected. The uterine horns of the control animals revealed neither epithelial modifications nor characteristic stromal changes except for slight hyperaemia and infiltration close to the intervention site during the first 2 weeks of healing. The ovaries were unaffected. 
PLATE 1

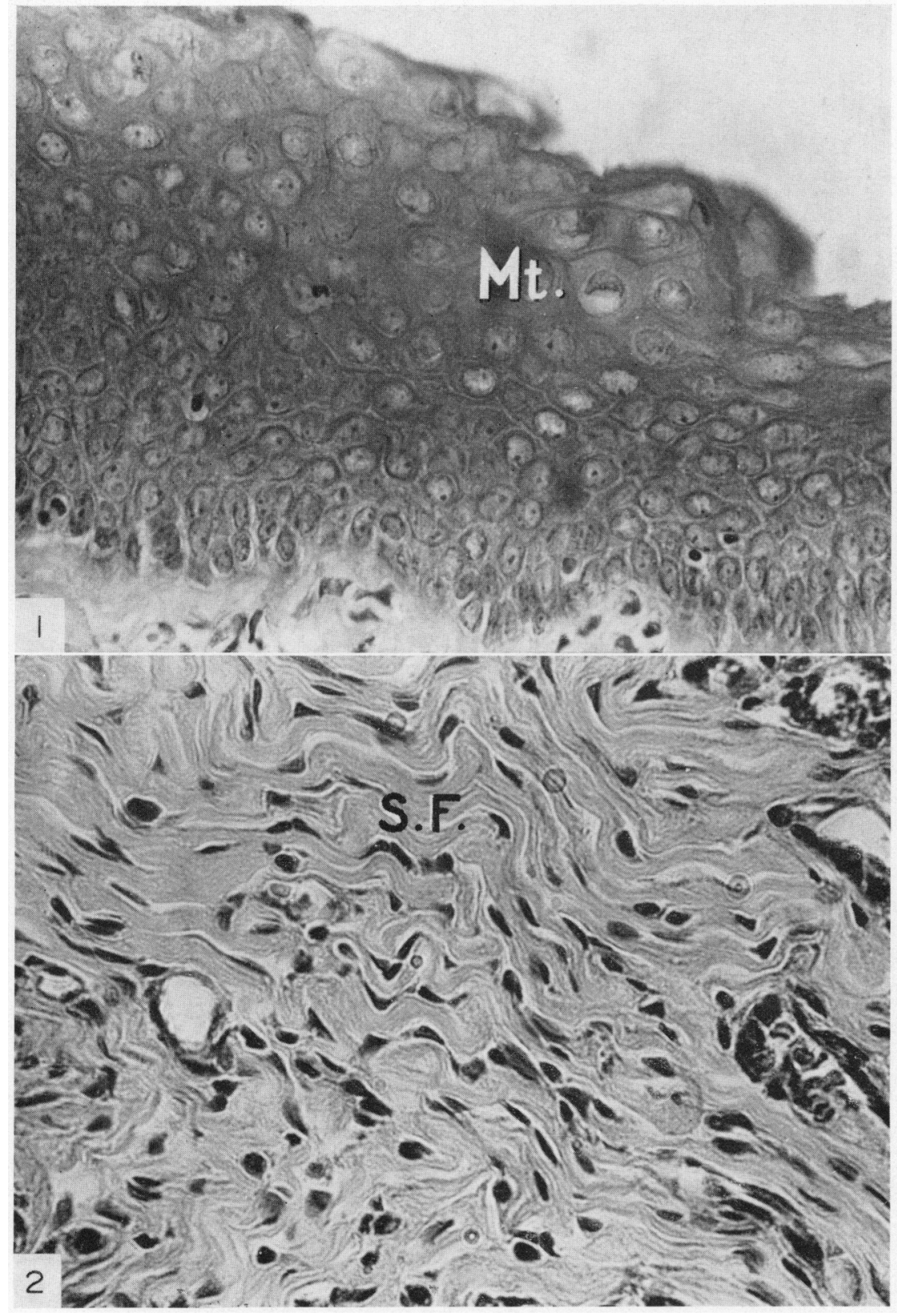

Fici. 1. Metaplasia to squamous stratified epithclium (Mt) in treated uterine horn, after a 7-week recovery period, following insertion of IUI) for 28 days. (Rat 38, left treated horn). H. and E. $\times 750$.

Fig. 2. Fibrosis of the deeper endonetrial stroma (S.F.) in treated horn, after a 4 -week recovery period, following insertion of ILD for 21 days. (Rat 96, right treated horm). H. and E. $\times 750$. 


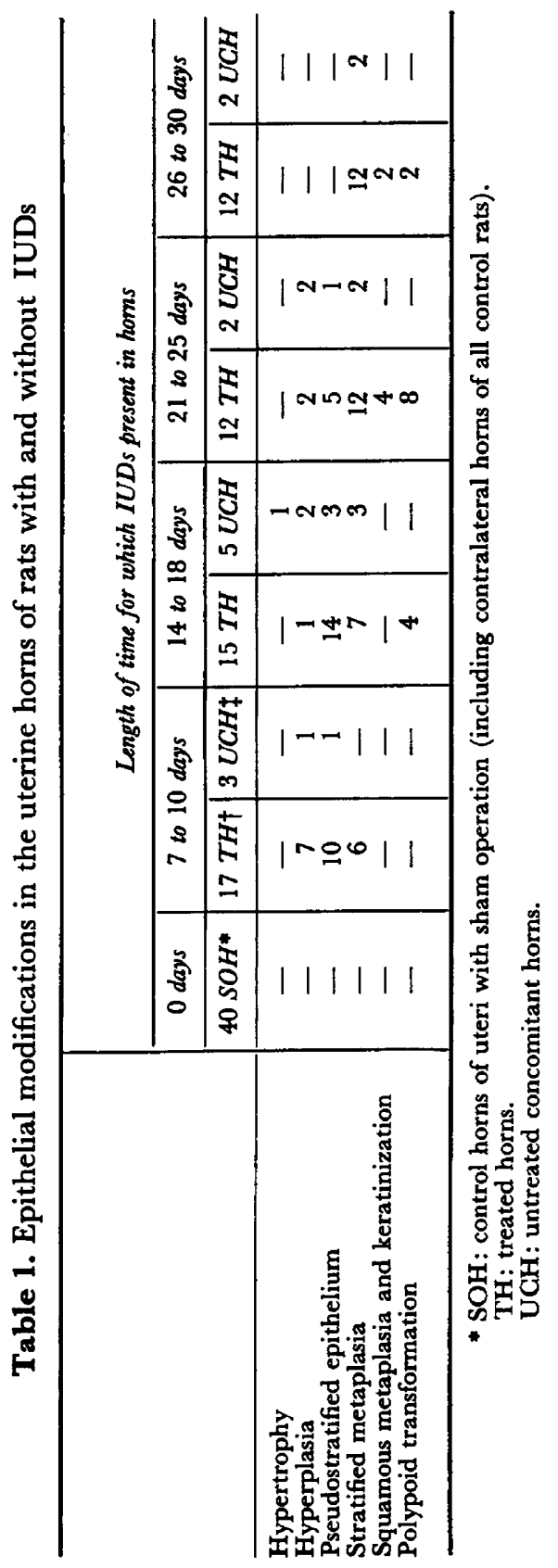


Following endometrial injury, persistent structural alterations of varying degrees developed during the recovery period. Severe epithelial changes were associated with more extensive stromal alterations and the presence of an infiltrated fibrous stroma appeared to contribute to the derangement of adequate conditions for normal epithelial regeneration (Corfman \& Ritchart, 1967; Craig, 1967; Ober et al., 1968), resulting in the development of squamous and keratinized metaplasia. Many of the endometrial findings were similar to those seen following exposure to high levels of oestrogen. The consistently observed ovarian impairment may be related to a hyperoestrogenic effect on the regenerating endometrium, resulting in persistent damage (Sudha et al., 1967; Moore \& Bo, 1971; Warren \& Hawk, 1971).

The ovarian and endometrial conditions may also hinder implantation and gestation. When mated with the IUD in situ, the rats with bilateral IUDs showed no evidence of implantation, and developing embryos were found only

Table 2. Changes in the endometrial stroma of uterine horns of rats with and without IUDs

\begin{tabular}{l|c|c|c}
\hline \multicolumn{1}{c|}{$\begin{array}{c}\text { Stromal } \\
\text { changes }\end{array}$} & $\begin{array}{c}\text { Treated horns } \\
\text { IUD inserted (76) }\end{array}$ & $\begin{array}{c}\text { Concomitant horns } \\
\text { without IUD (32) }\end{array}$ & $\begin{array}{c}\text { Control horns, } \\
\text { sham operation (40) }\end{array}$ \\
\hline Hyperaemia & $63.0 \%$ & $32.0 \%$ & $5.0 \%$ \\
Oedema & $35.5 \%$ & $28.0 \%$ & $2.5 \%$ \\
Infiltration & $69.0 \%$ & $44.0 \%$ & $2.5 \%$ \\
Eosinophilia & $41.0 \%$ & $24.0 \%$ & - \\
Fibrosis & $61.0 \%$ & $32.0 \%$ & - \\
\hline
\end{tabular}

in the untreated horns of two out of thirty-two animals with unilateral intubation. In the animals mated following a recovery period, embryos were found in only about $10 \%$ of the previously untreated horns. In the bilaterally treated rats, gestation was not detected even after long recovery periods. Nevertheless, in $70 \%$ of all the experimental animals, repeated insemination was verified by vaginal smears during the recovery period. In view of the results obtained with control rats and previous observations on untreated animals, evidence of insemination may be taken as indicating that fertilization subsequently occurred. In many of the experimental rats, defective implantation with developmental arrest was detected. This impaired implantation may imply imperfect decidualization of the permanently damaged endometrium (Willson et al., 1965; Ledger et al., 1966; Craig, 1969), though damage to the blastocysts by the intraluminal macrophages of the infiltrates cannot be excluded (Sagiroglu, 1971). Embryotoxic effects of the uterine secretions provoked by the IUD should also be taken into consideration (Batta \& Chaudhury, 1968; Craig, 1969; DeBoer \& Anderson, 1971). The atypical corpora lutea and cystic degeneration of the ovaries following IUD treatment may reflect a retrograde effect of uterine origin on the ovaries, which includes luteolytic action and affects implantation and gestation (Warren \& Hawk, 1971).

These observations show that polyethylene tubes inserted for prolonged periods in the uterine horns of rats may cause fundamental and persistent damage to the endometrium with concomitant changes in the contralateral 
horns, and may induce persistent ovarian injury. The damage could impede normal endometrial regeneration after removal of the IUD and lead to permanent pathological modifications affecting subsequent fertility.

\section{REFERENGES}

Batta, S. K. \& Chaudhury, R. R. (1968) Antifertility effect of an intra-uterine silk thread suture in rats with a connection between the two uterine horns. F. Reprod. Fert. 16, 371.

Corfman, P. A. \& Rrtcharr, R. M. (1967) Induction in rats of uterine epidermoid carcinomas by plastic and stainless steel intrauterine devices. Am. 7. Obstet. Gynec. 96, 987.

Craig, J. M. (1967) The effect of intrauterine string on the rat uterus. Fert. Steril. 18, 466.

CRAIG, J. M. (1969) Effect of an intrauterine device on rat blastocysts and deciduomata formation. Fert. Steril. 20, 424.

DeBoer, K. F. \& ANDERson, L. L. (1971) Survival of embryos transferred into the IUD-bearing uterus of the rat. F. Reprod. Fert. 25, 375.

Ledger, W. J., Virkar, K. D. \& Irvin, L. A. (1966) Effect of plastic intrauterine device upon implantation in the rabbit. Obstet. Gynec., N.Y. 28, 521.

Moore, P. J. \& Bo, W. J. (1971) Morphology of the rat uterus after prolonged exposure to a foreign body. Lab. Invest. 24, 25.

Ober, W. B., Sobrero, A. J., Kurman, R. \& Gold, S. (1968) Endometrial morphology and polyethylene intrauterine devices. Obstet. Gynec., N.Y. 32, 782.

Sagiroglu, I. (1971) Phagocytosis of spermatozoa in the uterine cavity of women using an intrauterine device. Int. J. Fert. 16, 1.

Sudha, S., Chakravarti, R. N. \& Chaudhury, R. R. (1967) Effect of an IUD in the rat. Indian. $\mathcal{J}$. med. Res. 55, 1015.

Warren, J. W. \& HAWK, H. W. (1971) Enhancement by exogenous estradiol of IUD-induced luteal regression in the ewe. Biol. Reprod. 4, 48.

Willson, J. R., Ledger W. J. \& ANDrios, G. J. (1965) The effect of an intrauterine contraceptive on the histologic pattern of the endometrium. Am. J. Obstet. Gynec. 93, 802. 